\title{
PENGUKURAN KINERJA WAKTU DAN BIAYA PROYEK PEMBANGUNAN JETTY MENGGUNAKAN METODE EARNED VALUE
}

\author{
Nurul Romadhonnia ${ }^{1}$, Mohamad Ferdaus Noor Aulady ${ }^{2)}$, Felicia Tria Nuciferani ${ }^{2)}$ \\ ${ }^{1}$ Alumni Jurusan Teknik Sipil, Fakultas Teknik Sipil dan Perencanaan, Institut Teknologi Adhi \\ Tama Surabaya \\ ${ }^{2}$ Jurusan Teknik Sipil, Fakultas Teknik Sipil dan Perencanaan, Institut Teknologi Adhi Tama \\ Surabaya \\ Email: nurulromadhonnia@gmail.com
}

\begin{abstract}
Abstrak
Seiring dengan kebijakan pemerintah terkait pembangunan infrastruktur, maka pelaksanaan proyek infratuktur juga harus berjalan dengan baik. Oleh karena itu perlu adanya pengukuran kinerja pada proyek infrastruktur. Penelitian ini bertujuan untuk mengukur kinerja biaya dan waktu proyek Jetty dengan menggunakan metode earned value analysis. Earned Value (EV) adalah sebuah metode yang dapat mengukur kinerja sebuah proyek dengan mengintegrasikan biaya dan waktu. Hasil penelitian menujukan bahwa kinerja proyek pembangunan Jetty PT. Kias yang berlokasi di Manyar, Gresik mengalami keterlambatan dari jadwal yang sudah direncanakan. Ini ditandai dari nilai SV yang berada pada posisi negatif dan SVI yang kurang dari nilai 1. Jika kinerja ini tetap dipertahankan oleh kontraktor, kontraktor selaku pelaksana proyek juga mengalami kerugian keuangan bila dibandingan dengan anggaran rencana yang ada.
\end{abstract}

Kata kunci: Kinerja, Proyek, Earned Value Analysis

\begin{abstract}
Along with government policies related to infrastructure development, the implementer of the infrastructure project must be succeeded. Therefore, it is necessary to measure performance in infrastructure projects. This research aim to measure project performance of Jety project according to the cost and time using earned value analysis. Earned value analysis are project perfomance measurment tools that can intregated between cost and time. The result show that the performance of PT. Kias Jety Project, Manyar, Gresik are experiencing delays according the shecdule plan. This marked with $S V$ value that have negative valuable and SVI value are less than 1. If this performance are continued by the contractor, it will make contractor having loss comparing with budget plan.
\end{abstract}

Keywords: Performance, Project, Earned Value Analysis 


\section{PENDAHULUAN}

Tujuan Pembangunan Nasional di Indonesia adalah untuk dapat mewujudkan kesejahteraan kehidupan masyarakat yang adil dan makmur (Budianta, 2010). Oleh karena itu dasawarsa ini pemerintah sangat intens untuk melakukan pembangunan proyek infrastruktur, khususnya pembangunan dermaga serta Jetty dikarenakan karakteristik Indonesia yang merupakan negara kepulauan. Sehingga pembangunan dermaga dan Jetty menjadi prioritas utama.

Pekerjaan ini merupakan suatu kegiatan yang tidak rutin dan tidak berulang, memiliki jangka waktu tertentu untuk mendapatkan hasil sesuai dengan yang diharapkan (Dini \& Juliantina, 2013). Sedangkan menurut pakar lain menyebutkan Proyek adalah gabungan dari sumber daya seperti manusia, material, peralatan dan modal/biaya yang dihimpun dalam suatu wadah organisasi sementara untuk mencapai sasaran dan tujuan (Husen, 2009). Karakteristik proyek yang unik membuat sebuah proyek satu dengan proyek lain tidak akan pernah sama meskipun jenis bangunan yang dibangun merupakan bangunan yang hampir mirip. Terlebih lagi faktor manusia yang terlibat dalam sebuah proyek akan mempengaruhi kinerja dari sebuah proyek (Meliasari \& Indrayadi, 2013).

Agar proyek pembangunan Jetty dapat terlaksana dengan baik, maka diperlukan sebuah pengendalian agar tidak terjadi kendala yang berarti. Agar pengendalian proyek dapat berjalan efektif, maka kita perlu tahu bagaimana kinerja proyek Jetty saat ini dengan kondisi proyek yang ada. sedikit penelitian yang mengukur kinerja proyek Jetty. (Halim, Noviananto, \& Sihotang, 2008) misalnya melakukan penelitian tentang analisis pengukuran kinerja keuangan global pada proyek pengelolaan tabungan dengan menggunakan earned value analysis di PT. Aprisma Indonesia. Hasil dari penelitian ini adalah untuk mengukur bagaimana proyek Manajemen Kas Global dilakukan sesuai dengan waktu dan rencana anggaran di PT. Aprisma Indonesia. Sedangkan (Nasroem, 2014) melakukan penelitian yang bertujuan mengetahui kinerja biaya dan waktu pelaksanaan terhadap nilai kontrak serta mengetahui besarnya perkiraan biaya dan waktu yang diperlukan untuk penyelesaian proyek. Hasil dari penelitian menunjukkan dengan analisa tersebut kontraktor dapat mendapatkan keuntungan di akhir proyek. Berbeda dengan (Rantung, Sompie, \& Mandagi, 2014), mereka melakukan penelitian tentang analisis pengendalian biaya dan jadwal pada tahap pelaksanaan konstruksi dengan analisis nilai hasil (earned value analysis) studi kasus pada proyek bangunan pengaman pantai di Provinsi Sulawesi utara. Hasil penelitian menunjukkan bahwa rata-rata nilai hasil 20 paket dengan menggunakan Varian Biaya (CV) lebih besar daripada menggunakan Varian Jadwal (SV).

Studi ini bertujuan untuk mengukur kinerja biaya dan waktu proyek Jetty dengan menggunakan metode earned value analysis. Earned Value (EV) adalah sebuah metode yang digunakan untuk mengukur kineja sebuah proyek dengan mengintegrasikan biaya dan waktu. pengukuran kedua indikator tersebut tidak dilakukan secara terpisah sehingga akan mudah dipahami oleh pelaksana di lapangan. Selain itu dengan pengukuran kinerja biaya dan waktu kita dapat mengidentifikasikan kinerja keseluruhan proyek dan kemudian memprediksi kinerja biaya dan waktu penyelesaian proyek.

Hasil dari evaluasi proyek ini juga bisa dijadikan Early Warning bagi pelaku proyek untuk mengambil tindakantindakan yang diperlukan agar pembengkakan biaya atau keterlambatan dapat dicegah (Priyo \& Wibowo, 2008). Dipilihnya proyek pembangunan Jetty di Manyar, Gresik, Jawa Timur ini dikarenakan kompleksitas proyek tersebut dan durasi yang cukup lama. 
Sehingga dapat digunakan juga untuk melihat sejauh mana earned value analisis dapat digunakan dalam proyek yang kompleks dan jangka waktu yang cukup lama.

\section{METODE}

Metode EV dimulai dari pengumpulan data. Baik data primer maupun data sekunder. Data sekunder merupakan data yang diperoleh untuk menunjang penelitian ini. Adapun data yang dimaksud adalah data Rencana Anggaran Biaya (RAB), Time Schedule, Laporan Mingguan. Sedangkan data primer berupa wawancara dan tinjauan lapangan. Dari data yang ada maka kita dapat melakukan Analisa data untuk menghitung indikator capaian kerja dan analisa kerja.

Indikator capaian kerja terdiri dari beberapa item yaitu Actual Cost of Work Performed (ACWP) yang merupakan jumlah biaya aktual dari pekerjaan yang telah dikerjakan sampai waktu tertentu. Indikator ini didapatkan dengan cara menghitung total biaya yang sudah dikeluarkan oleh kontraktor sampai pada titik pengukuran kinerja. Indikator yang kedua yaitu Budgeted Cost of Work Performed (BCWP). Menggambarkan anggaran rencana proyek pada periode tertentu terhadap apa yang telah dikerjakan pada volume pekerjaan aktual. Indikator ini didapatkan dengan cara melihat time schedule sampai pada titik peninjauan (bobot realisasi mingguan) dengan biaya mingguan yang didapatkan dari laporan keuangan mingguan. Dan terakhir adalah Budgeted Cost of Work Scheduled (BCWS) adalah besarnya biaya yang dianggarkan untuk pekerjaan yang dijadwalkan (Soeharto, 2001). Diperoleh dengan cara melihat data rencana anggaran biaya.

Adapun setelah mendapatkan 3 indikator tersebut dilanjutkan dengan menghitung Analisa varians dan Index kinerja. Kedua analisa ini nantinya digunakan sebagai pengukuran kinerja sebuah proyek. Dimulai dari analisa varians Di mana analisa ini digunakan untuk mengetahui sejauh mana varians atau penyimpangan proyek yang dilaksanakan terhadap rencana proyek. Adapun Analisa varians yang dimaksud dapat di rumuskan sebagai berikut (Soeharto, 2001):

Cost Variance $(\mathrm{CV})$

$$
C V=B C W P-A C W P
$$

Schedule variance $(S V)$

$$
S V=B C W P-B C W S
$$

Nilai $S V$ dan $C V$ nantinya dapat menentukan penilaian kinerja proyek. Tabel 1 menunjukkan arti dari nilai varians. Jika hasil nilai dari SV bernilai positif dan nilai $\mathrm{CV}$ bernilai positif maka kinerja proyek adalah proyek dilaksanakan lebih cepat dari rencana yang ada begitu pula anggaran yang digunakan lebih kecil dari anggaran yang direncanakan. Proyek dikatakan mempunyai kinerja buruk dari segi biaya dan waktu jika nilai SV dan CV bernilai negatif.

Tabel 1 Arti nilai perhitungan SV dan CV (Soeharto, 2001)

\begin{tabular}{ccl}
$\begin{array}{c}\text { Varians } \\
\text { Jadwal } \\
(\text { SV) }\end{array}$ & $\begin{array}{c}\text { Varians Biaya } \\
(\text { CV) }\end{array}$ & \multicolumn{1}{c}{ Keterangan } \\
\hline Positif & Positif & $\begin{array}{l}\text { Pekerjaan lebih cepat dari jadwal dan biaya } \\
\text { lebih kecil dari anggaran }\end{array}$ \\
\hline Nol & Positif & $\begin{array}{l}\text { Pekerjaan sesuai jadwal dan biaya lebih kecil } \\
\text { dari anggaran }\end{array}$ \\
\hline Positif & Nol & $\begin{array}{l}\text { Pekerjaan lebih cepat dan biaya sesuai } \\
\text { anggaran }\end{array}$ \\
\hline Nol & Nol & Pekerjaan sesuai jadwal dan anggaran \\
\hline
\end{tabular}




\begin{tabular}{ccl}
$\begin{array}{c}\text { Varians } \\
\text { Jadwal } \\
(\text { SV })\end{array}$ & $\begin{array}{c}\text { Varians Biaya } \\
(\mathbf{C V})\end{array}$ & \multicolumn{1}{c}{ Keterangan } \\
\hline Negatif & Negatif & $\begin{array}{l}\text { Pekerjaan selesai terlambat dan biaya lebih } \\
\text { tinggi dari anggaran }\end{array}$ \\
\hline Nol & Negatif & $\begin{array}{l}\text { Pekerjaan terlaksana sesuai jadwal dan biaya } \\
\text { lebih tinggi dari anggaran }\end{array}$ \\
\hline Negatif & Nol & $\begin{array}{l}\text { Pekerjaan selesai terlambat dan biaya sesuai } \\
\text { anggaran }\end{array}$ \\
\hline Positif & Negatif & $\begin{array}{l}\text { Pekerjaan selesai lebih cepat dengan biaya } \\
\text { melebihi anggaran }\end{array}$ \\
\hline Negatif & Positif & $\begin{array}{l}\text { Pekerjaan selesai terlambat dan biaya lebih } \\
\text { rendah dari anggaran }\end{array}$ \\
\hline
\end{tabular}

Setelah mendapatkan nilai $S V$ dan $C V$ maka selanjutnya menentukan Indeks kinerja. Indeks Kinerja didapatkan dengan perumusan (Soeharto, 2001):

Cost Performance Index (CPI)

$$
C P I=\frac{B C W P}{A C W P}
$$

Schedule Performance Index (SPI)

$$
S P I=\frac{B C W P}{B C W S}
$$

Nilai $C P I$ dan SPI melambangkan kinerja dari proyek. Jika nilai $C P I$ dan $S P I$ bernilai < 1, maka kinerja proyek dinyatakan terlambat dan melebih rencana anggaran. Sedangkan jika bernilai $>1$, maka kinerja proyek tidak mengalami keterlambatan dan anggaran pelaksaan berada di bawah anggaran rencana.

Selanjutnya setelah mendapatkan kinerja dari proyek tersebut, maka selanjutnya kita dapat melakukan perkiraan pengeluaran biaya di akhir proyek serta waktu pelaksanaan akhir proyek berdasarkan kinerja yang sudah diukur. Adapun untuk perkiraan biaya pelaksanaan proyek atau dapat dibagi menjadi 2 yaitu untuk perkiraan biaya pekerjaan tersisa estimate to complete (ETC) dan untuk biaya total pada akhir proyek estimate at complete (EAC). ETC digunakan untuk melihat apakah ada sisa biaya pada akhir proyek atau besaranya keuntungan yang didapatkan kontraktor. Sedangkan ETC digunakan untuk melihat biaya keseluruhan proyek dan kemudian dibandingkan dengan biaya rencana sehingga dapat diketahui berapa penyimpangan yang terjadi. Adapun perumusan ETC dan EAC didapatkan dari persamaan berikut (Husen, 2009):

\section{Estimate at Completion}

$$
E A C=A C W P+E T C
$$

Estimate to Complete untuk progress

fisik $<50 \%$

$$
E T C=\text { Anggaran }-B C W P
$$

Estimate to Complete untuk progress

fisik $>50 \%$

$$
E T C=\frac{(\text { Anggaran }- \text { BCWP })}{C P I}
$$

Sedangkan untuk perkiraan waktu penyelesaian proyek atau Time Estimates (TE) dapat di hitung dengan rumus (Husen, 2009)

Time Estimate

$$
\mathrm{TE}=\mathrm{ATE}+\left(\frac{\mathrm{OD}-(\mathrm{ATE} \times \mathrm{SPI})}{\mathrm{SPI}}\right)
$$

Keterangan:

$\begin{array}{ll}\text { TE }(\text { Time } & \text { Perkiraan waktu } \\ \text { Estimated }) & : \text { penyelesaian }\end{array}$




$\begin{array}{ll}\text { ATE (Actual } & \begin{array}{l}\text { Waktu yang te } \\ \text { Time Expended) }\end{array} \\ \text { ditempuh. } \\ \begin{array}{l}\text { OD (Original } \\ \text { Duration) }\end{array} & \text { Waktu yang } \\ \end{array}$

Hasil dari perkiraan baik dari segi dan waktu dapat menjadi early warning bagi kontraktor. Jika pengukuran kinerja mereka mengalami keterlambatan dan pembengkakan biaya maka hasil perkiraan ini dapat memperlihatkan sejauh mana kontraktor terlambat dan biaya yang harus dan telah dikeluarkan untuk proyek tersebut.

\section{HASIL DAN PEMBAHASAN}

Pengukuran kinerja pada proyek pembangunan Jetty di Gresik ini ditinjau pada pekerjaan minggu ke 88-100. Hal ini dikarenakan pada minggu tersebut terjadi perbedaan signifikan antara jadwal rencana dan realisasi di lapangan.

Berdasarkan data yang ada maka aada minggu ke - 88 didapatkan nilai $A C W P$ sebesar Rp. 232.538.625 sedangkan BCWP sebesar Rp. 255.732.195 dan untuk BCWS sebesar Rp. 435.243.430. kemudian dilakukan perhitungan berdasarkan persamaan (1) dan (2). Di mana persamaan tersebut digunakan untuk mengetahui nilai dari Cost Variance dan Schedule Variance $(C V$ dan $S V)$.

Tabel 2 Nilai $S V$ dan $C V$ pada masing-masing minggu peninjauan proyek.

\begin{tabular}{|c|c|c|c|c|c|c|c|c|c|}
\hline \multicolumn{10}{|c|}{ Nilai SV dan CV } \\
\hline \multirow{4}{*}{ SV } & $\begin{array}{l}\text { Mg ke- } \\
97\end{array}$ & $=$ & -292121778 & $\begin{array}{l}\text { Mg ke- } \\
92\end{array}$ & $=$ & $\begin{array}{c}- \\
352504314,2\end{array}$ & $\begin{array}{l}\text { Mg ke- } \\
88\end{array}$ & $=$ & $\begin{array}{c}- \\
179511234,9\end{array}$ \\
\hline & $\begin{array}{l}\text { Mg ke- } \\
98\end{array}$ & $=$ & $\begin{array}{c}- \\
183352317,6\end{array}$ & $\begin{array}{c}\text { Mg ke- } \\
93\end{array}$ & $=$ & $\begin{array}{c}- \\
227546708,7\end{array}$ & $\begin{array}{c}\text { Mg ke- } \\
89\end{array}$ & $=$ & $\begin{array}{c}- \\
414405280,9\end{array}$ \\
\hline & $\begin{array}{l}\text { Mg ke- } \\
99\end{array}$ & $=$ & $\begin{array}{c}- \\
169105185,9\end{array}$ & $\begin{array}{l}\text { Mg ke- } \\
94\end{array}$ & $=$ & 59821597,45 & $\begin{array}{l}\text { Mg ke- } \\
90\end{array}$ & $=$ & $\begin{array}{c}- \\
318999579,1 \\
\end{array}$ \\
\hline & $\begin{array}{l}\text { Mg ke- } \\
100\end{array}$ & $=$ & $\begin{array}{c}- \\
143429001,3\end{array}$ & $\begin{array}{l}\text { Mg ke- } \\
95\end{array}$ & $=$ & $\begin{array}{c}- \\
232581427,6\end{array}$ & $\begin{array}{l}\text { Mg ke- } \\
91\end{array}$ & $=$ & $\begin{array}{c}- \\
432821140,2\end{array}$ \\
\hline \multirow{4}{*}{ CV } & $\begin{array}{l}\text { Mg ke- } \\
97\end{array}$ & $=$ & 43 & $\begin{array}{l}\text { Mg ke- } \\
92\end{array}$ & $=$ & $\begin{array}{c}- \\
94812470,57\end{array}$ & $\begin{array}{l}\text { Mg ke- } \\
88\end{array}$ & $=$ & 23193570,05 \\
\hline & $\begin{array}{c}\text { Mg ke- } \\
98\end{array}$ & $=$ & -66861230 & $\begin{array}{c}\text { Mg ke- } \\
93\end{array}$ & $=$ & $\begin{array}{c}- \\
197856986,1\end{array}$ & $\begin{array}{l}\text { Mg ke- } \\
89\end{array}$ & $=$ & $\begin{array}{c}- \\
56840129,61\end{array}$ \\
\hline & $\begin{array}{c}\text { Mg ke- } \\
99 \\
\end{array}$ & $=$ & -36542411 & $\begin{array}{l}\text { Mg ke- } \\
94\end{array}$ & $=$ & 44892403,95 & $\begin{array}{l}\text { Mg ke- } \\
90\end{array}$ & $=$ & 86250407,24 \\
\hline & $\begin{array}{l}\text { Mg ke- } \\
100\end{array}$ & $=$ & -147270057 & $\begin{array}{l}\text { Mg ke- } \\
95\end{array}$ & $=$ & $\begin{array}{c}- \\
32341848,59\end{array}$ & $\begin{array}{l}\text { Mg ke- } \\
91\end{array}$ & $=$ & $\begin{array}{c}- \\
104593144,1\end{array}$ \\
\hline
\end{tabular}

Berdasarkan Tabel 2 Nilai $S V$ dan $C V$ untuk minggu ke -88 adalah 179511234,9 dan 23193570.05. sesuai dengan Tabel 1 maka ini berarti nilai $S V$ adalah negatif dan $C V$ adalah positif. Di mana pekerjaan lebih lambat dari yang direncanakan namun tidak terjadi pembengkakan biaya. Kinerja proyek mulai mengalami penurunan pada minggu ke - 89 di mana nilai $S V$ dan $C V$ adalah -414405280.9 dan -56840129.61 . yang berati pekerjaan terlambat dari jadwal rencana dan biaya di atas rencana yang ada.
Namun kinerja proyek sempat mengalami kenaikan pada minggu ke -90 di mana nilai $S V$ dan $C V$ adalah 318999579.1 dan 86250407.24. namun setelah itu kinerja proyek menurun terus terkecuali minggu ke 94. Pada dasarnya kinerja proyek pada minggu ke -88 sampai dengan minggu ke -100 hampir sama yaitu mengalami keterlambatan dan biaya yang dikeluarkan berada di atas anggaran rencana .

Tabel $\mathbf{3}$ merupakan hasil perhitungan nilai $C P I$ dan SPI pada masing-masing minggu peninjauan proyek. Nilai $C P I$ dan SPI pada minggu ke -88 adalah 
sebesar 0.58 dan 1.1 yang berarti proyek mengalami keterlambatan namun anggaran yang digunakan masih di bawah anggaran rencana, yang berarti analisa varians dan indeks kinerja menunjukkan hal yang sama. Indeks kinerja juga menyatakan hal yang sama dengan nilai varians. Dari minggu ke 88
- 100 rata-rata proyek mengalami keterlambatan dan biaya berada di atas anggaran rencana. Nilai kinerja keuangan berada di bawah anggaran rencana hanya pada minggu ke -88, minggu ke - 90 dan minggu ke -94 . Hal yang sama juga terjadi pada analisa varians.

Tabel 3 Nilai SPI dan CPI pada masing-masing peninjauan proyek

\begin{tabular}{|c|c|c|c|c|c|c|c|c|c|}
\hline \multirow{4}{*}{ SPI } & Mg ke-97 & $=$ & 0,230 & Mg ke-92 & $=$ & 0,350 & Mg ke- 88 & $=$ & 0,588 \\
\hline & Mg ke-98 & $=$ & 0,523 & Mg ke-93 & $=$ & 0,305 & Mg ke-89 & $=$ & 0,342 \\
\hline & Mg ke-99 & $=$ & 0,560 & Mg ke-94 & $=$ & 1.218 & Mg ke-90 & $=$ & 0,493 \\
\hline & Mg ke-100 & $=$ & 0,476 & Mg ke-95 & $=$ & 0,151 & Mg ke-91 & $=$ & 0,202 \\
\hline \multirow{4}{*}{ CPI } & Mg ke-97 & $=$ & 0,438 & Mg ke-92 & $=$ & 0,667 & Mg ke- 88 & $=$ & 1,100 \\
\hline & Mg ke-98 & $=$ & 0,750 & Mg ke-93 & $=$ & 0,335 & Mg ke-89 & $=$ & 0,791 \\
\hline & Mg ke-99 & $=$ & 0,855 & Mg ke-94 & $=$ & 1,155 & Mg ke-90 & $=$ & 1,384 \\
\hline & Mg ke-100 & $=$ & 0,470 & Mg ke-95 & $=$ & 0,561 & Mg ke-91 & $=$ & 0,511 \\
\hline
\end{tabular}

Selanjutnya dilakukan perkiraan biaya dan waktu penyelesaian berdasarkan kinerja proyek yang ada. perhitungan perkiraan penyelesaian biaya dan waktu pekerjaan dilakukan dengan meninjau titik 97-100. Dikarenakan pada titik tersebut kinerja proyek semakin terus menurun tanpa ada kenaikan sama sekali. Persentase pekerjaan sampai dengan minggu ke-100 telah mencapai di atas 50\% maka untuk memproyeksikan anggaran untuk pekerjaan yang tersisa digunakan persamaan (7).

Didapatkan nilai ETC yaitu sebesar Rp. 12.174.557.267 sedangkan nilai $E A C$ adalah sebesar Rp. 32.463. 638.180. dari nilai tersebut dapat dilakukan analisa penambahan atau penurunan biaya aktual terhadap anggaran proyek. Dengan cara sebagai berikut

$$
\begin{aligned}
& 100 \%-\left(\frac{E A C}{\text { Anggraan } \times 100 \%}\right) \\
& =100 \% \\
& -\left(\frac{R p .32 .463 .638 .180}{42.399 .237 .200 \times 100 \%}\right) \\
& =23,43 \%
\end{aligned}
$$

Ini berarti nilai biaya mengalami penurunan sebesar $24.43 \%$ dari biaya yang dianggarkan untuk pekerjaan yang telah dilaksanakan.
Langkah terakhir yaitu memperkirakan waktu penyelesaian proyek. Proyek direncanakan berlangsung selama 826 hari. Peninjauan di lakukan pada akhir minggu ke-100 yaitu pada hari ke-643 proyek berjalan. Sehingga diperoleh nilai $T E$ adalah sebesar $1148,366 \approx$ 1149 hari.

Berarti ini menandakan jika kinerja proyek tetap seperti ini tanpa mengalami perbaikan, maka proyek akan selesai pada hari ke 1149 hari atau mengalami keterlambatan selama 323 hari dari jadwal yang direncanakan.

\section{KESIMPULAN}

Studi ini bertujuan untuk mengukur kinerja proyek pembangunan Jetty di Gresik, Jawa Timur yang mana proyek tersebut mempunyai durasi pekerjaan dan kompleksitas yang tinggi. Dari hasil analisa earned value didapatkan bahwa kinerja proyek adalah terlambat dan biaya yang dikeluarkan melebih anggaran perencanaan. Jika kinerja proyek tetap seperti ini, maka kontraktor akan menerima kerugian sebesar $23,43 \%$ dan 
keterlambatan selama 323 hari yang akan berujung pada penalti.

\section{UCAPAN TERIMAKASIH}

Ucapan terima kasih disampaikan oleh penulis kepada pihak yang telah membatu dalam keseluruhan dari penelitian ini. Serta redaksi yang telah memberikan koreksi pada artikel ini.

\section{DAFTAR PUSTAKA}

Budianta, A. (2010). Pengembangan Wilayah Perbatasan Sebagai Upaya Pemerataan Pembangunan Wilayah Di Indonesia. Jurnal SMARTek, 8(1), 72-82.

Dini, G. R., \& Juliantina, I. (2013). Pengendalian Proyek Pembangunan Lanjutan SMA Negeri Internasional Sumatera Selatan Palembang Dengan Metode Earned Value. Jurnal Teknik Sipil dan Lingkungan, 1(1), 7.

Halim, A., Noviananto, S., \& Sihotang, R. P. (2008). The Analysis of Financial Performance Measurement of Global Cash Management Project using Earned Value Analysis at PT. Aprisma Indonesia. Journal of Applied Finance and Accounting, 1(1), 25-38.

Husen, A. (2009). Manajemen Proyek. Yogyakarta: Andi.

Meliasari, I., \& Indrayadi, M. (2013). Earned Value Analysis Terhadap Biaya Dan Waktu Pada Proyek Konstruksi (Studi Kasus Proyek Pembangunan Sarana/Prasarana Pengamanan Pantai). Jurnal Mahasiswa Teknik Sipil Universitas Tanjungpura, $2(2), 1-11$.

Nasroem. (2014). Performance Analysis Of Costs And Time With The Concept Of Earned ValueAnalysis On Building Construction Project. Kurva S Jurnal Mahasiswa, 4(1), 430-442.

Priyo, M., \& Wibowo, N. (2008). Konsep Earned Value dalam Aplikasi Pengelolaan Proyek Konstruksi. Jurnal Ilmiah Semesta Teknika, 11(2), 153-161.

Rantung, A. H. P., Sompie, B. F., \& Mandagi, R. J. M. (2014). Analisis Pengendalian Biaya Dan Jadwal Pada Tahap Pelaksanaan Konstruksi Dengan Analisis Nilai Hasil (Earned Value Analysis) Studi Kasus Pada Proyek Bangunan Pengaman Pantai Di Provinsi Sulawesi Utara. Jurnal Ilmiah Media Engineering, 4(3), 190203.

Soeharto, I. (2001). Manajemen Proyek: Dari Konseptual sampai Operasional (Vol. 2). Erlangga. 